\title{
Analysis of Internal Trust and Measurement in Farmer Cooperatives
}

\author{
Hui Min Shao \\ School of Economics and Management, Yunnan Normal \\ University \\ KunMing, China
}

\begin{abstract}
Farmer cooperatives, as a new agricultural management entity connecting rural households and markets, are an important force to promote structural reforms on the agricultural supply side, which greatly promotes the development of modern agriculture in China. This article points out trust problems in the development of farmer cooperatives. This article combines the relevant research content of literature data, designs a trust level scale, and uses the field survey data of 25 farmer cooperatives in four counties of Jianshui, Handan, Luquan and Changning in Yunnan Province to analyze and obtain the level of cooperative trust in the emerging Yunnan region. Meanwhile, this article concludes that Yunnan is on or below the medium level at this stage cooperative trust.
\end{abstract}

Keywords-Farmers' cooperatives; Internal trust; Yunnan province

\section{CONSTRUCTION OF FARMER COOPERATIVE INTERNAL TRUST SCALE}

This paper takes the farmers' cooperatives in Yunnan Province as the main sample, conducts empirical research on multi-cases and large sample data, and integrates the internal trust theory and cooperative management theory proposed in the mature market economy of developed countries with the management practice of Chinese cooperatives [1]. Localization research and exploration of cooperative development theories suitable for the specific situation of China's transition economy will help promote and promote the formation and development of the theory of cooperative society in China [2].

\author{
Tong Xing Li* \\ School of Economics and Management, Yunnan Normal \\ University \\ KunMing, China
}

This paper analyzes it through the Likert five-point scale method. The basic purpose of designing this scale is to evaluate the internal trust situation reasonably and lay a good foundation for the next influencing factors and relationship analysis. Through the above analysis and discussion, this paper designed 19 three-level evaluation indicators, and each independent variable was calculated by using the Likert 5-point scale method to obtain the corresponding value. The level of the value reflects the level of consent. "5" represents the strongest degree, "totally agree ", and "1" represents the weakest degree, and "strongly disagrees."

\section{RELIABILITY AND VALIDITY ANALYSIS OF THE INTERNAL TRUST SCALE OF FARMER COOPERATIVES}

\section{A. Data Sources}

The figures used in this paper are based on field surveys and interviews with 25 farmer cooperative members in the four counties of Jianshui, Handan, Luquan and Changning in Yunnan Province from August 2015 to October 2016. In order to ensure the integrity of the data, the data obtained from the six cooperatives in Jianshui and Changning were excluded. A total of 367 available samples were obtained. The recovery rate was $81.4 \%$. The analysis can find that the sample's age and education structure are roughly close to the normal segment, and the representativeness is relatively strong, which can basically reflect the actual situation of the internal trust in Yunnan's cooperatives (see Table 1). 
TABLE I.

TABLE 1 SOURCES AND COMPOSITION OF SURVEY SAMPLES

\begin{tabular}{llll}
\hline Survey area & Cooperatives & Frequency & $\%$ \\
\hline \multirow{3}{*}{ Lancang } & Hong Feng Coffee & 50 & 13.62 \\
& Guangyuan Tea & 51 & 13.90 \\
& Zhixin Beff & 13 & 3.54 \\
Zhongfu flue-cured tobacco & 25 & 6.81 \\
Yunlong planting & 25 & 6.81 \\
Bletilla striata planting & 25 & 6.81 \\
& Forest Industry Development & 25 & 6.81 \\
& Herbal planting & 25 & 6.81 \\
& Planted under the Xinhe Lin & 25 & 2.09 \\
& Linfuyuan Forest livestock & 15 & 3.27 \\
Agricultural machinery & Shed mushroom & 10 & 2.45 \\
walnut & 12 & 2.45 \\
& Luyuan Herbal Planting & 9 & 2.72 \\
& Hewei Village Ancient Tree Tea & 9 & 2.45 \\
& Silver konjac & 10 & 2.18 \\
Kejie Jia cuisine vegetables & 9 & 2.45 \\
Kass Chia breeder pig & 8 & 3.27 \\
\hline
\end{tabular}

B. Verification of reliability and validity of the internal trust scale of farmers' cooperatives

1) Trust Scale Exploratory Factor Analysis

The trust scale includes 19 basic measurements [3]. KMO and Bartlett's spherical tests are performed on different dimensions in sequence using SPSS22.0 software. Analysis of the inspection results can find that "A3", "A5", "A7", "B3", and "B7" have large ambiguities because the cross-load is too heavy and the load is less than 0.5 . The 14 measurement indicators. The principal component analysis method was used to extract the factors, and the factor with eigenvalue exceeding 1 was used as the common factor [4]. Analysis can find 4 factors after extraction, the corresponding explanatory powers are: $23.281 \%, 21.808 \%, 10.190 \%, 8.760 \%$. Total interpretation ability up to $64.039 \%$, more than $50 \%$, this shows that the four factors we have obtained are highly representative. The load factor of each measurement item exceeds 0.5 , and the cross load is less than 0.4. Each measurement item is in the corresponding factor, indicating that the scale given in this paper has a good structural validity.

\section{2) Trust scale reliability analysis}

After examination and analysis, $\mathrm{KMO}=0.737$ was obtained, and the Bartlet chi-square test was $8108.245, \mathrm{P}<.001$. Using the principal component analysis method and using the basic requirement that the eigenvalue is not less than 1 , four common factors can be obtained [5]. In the process of reliability analysis, the four factors of Cronbach's Alpha all exceeded 0.7, and the CTTC values exceeded 0.5. From the point of view of
"Cronbach's Alpha Values Deleted", deleting any measurement item will not increase the Cronbach's Alpha coefficient, which can also reflect the variable's high reliability level. Based on the above results, it can be concluded that the scale given in this paper has good reliability and validity and can be used to evaluate the internal trust of the cooperative.

\section{THE FARMERS COOPERATIVES INTERNAL TRUST SCALE VERIFICATION}

\section{A. Calculation of trust index weights}

The weight of each indicator in this paper is mainly obtained through analysis of the coefficients and factor loads corresponding to different observation variables of the structural model [6]. First, the load corresponding to each indicator is accumulated, and the cumulative value of each indicator's load can be correspondingly obtained the weight. At the same time, we also consulted relevant experts. Through analysis, we can conclude that the weights of trust in the two dimensions of relationship and system are 0.622 and 0.378 . Similarly, the weights corresponding to different indicators in each secondary dimension can also be analyzed. See the specific table2 below. 
TABLE II. WEIGHTS OF TRUST INDICATORS

\begin{tabular}{cccc}
\hline First-level indicators & Second-level indicators & Third-level indicators & Weights \\
\hline & Relationship trust & Common emotion & 0.316 \\
Trust & 0.622 & Common values and & interests \\
& Institutional trust & System establishment & 0.306 \\
& 0.378 & Institutional & 0.137 \\
& implementation & 0.241 \\
\hline
\end{tabular}

\section{B. Calculation of trust level}

This article will evaluate the degree of trust of the cooperative through the scale indicators obtained finally, and the data used is from the 367 questionnaires obtained previously. The score calculation results for each indicator in the questionnaire are specifically shown in Table 3below:

TABlE III. TRust LeVel Calculation Results

\begin{tabular}{|c|c|c|c|}
\hline Survey area & Cooperatives & Trust level & level \\
\hline \multirow{3}{*}{ Lancang } & Hong Feng Coffee & 1.43 & Lower \\
\hline & Guangyuan Tea & 1.47 & Lower \\
\hline & Zhixin Beff & 2.02 & general \\
\hline \multirow{6}{*}{ Luquan } & Zhongfu flue-cured tobacco & 1.99 & Lower \\
\hline & Yunlong planting & 1.85 & Lower \\
\hline & Bletilla striata planting & 2.13 & general \\
\hline & Forest Industry Development & 1.81 & Lower \\
\hline & Herbal planting & 1.72 & Lower \\
\hline & Planted under the Xinhe Lin & 1.8 & Lower \\
\hline \multirow{10}{*}{ Changning } & Linfuyuan Forest livestock & 2.33 & general \\
\hline & Agricultural machinery & 2.01 & general \\
\hline & Shed mushroom & 1.48 & Lower \\
\hline & Zhengqiang walnut & 2.86 & general \\
\hline & Luyuan Herbal Planting & 2.38 & general \\
\hline & Hewei Ancient Tree Tea & 2.2 & general \\
\hline & Silver konjac & 2.91 & general \\
\hline & Kejie Jia cuisine vegetables & 2.72 & general \\
\hline & Kass Chia breeder pig & 2.45 & general \\
\hline & Fuhua Rongxin Walnut & 2.69 & general \\
\hline
\end{tabular}

\section{CONCLUSIONS AND DISCUSSION}

After analysis, a comprehensive score of 2.12 can be obtained. Therefore, from the overall situation, at this stage, the members of the Yunnan Provincial Cooperatives have a weaker degree of trust in the cooperatives. This result is basically consistent with the actual development of cooperatives in Yunnan in the near future. Through the scale, we can find that the comprehensive score of the trust level of the members of the Jixian County Cooperative is 1.64 , and the trust level is poor, which is lower than the average situation of the province; Luquan County has a comprehensive score of 1.88 , which is relatively low in the survey. Low level; Changning County has a comprehensive score of 2.40 , with a general level of trust, and is above the provincial average. These results are basically consistent with the findings of actual research. Many cooperatives in Chang ning County have applied the Internet+ model and are more concerned with brand image. Each cooperative has a relatively large scale, has formed a healthy development, and is conducive to improving members' trust in the organization. On the other hand, the cooperatives in the two districts of Handan and Luquan are not large scale, have poor concentration, and have low operating standards. They often face the situation of insufficient funds. Many cooperatives are located in the upper reaches of the industrial chain and provide assistance to the members. The support is limited to training 
and information sharing at low levels; the proportion of cooperatives with joint bargaining and marketing services is very low. Most of the agricultural product sales rely on foreign merchants to purchase locally or directly in the local market, and the flexibility is poor. Under such circumstances, the cooperatives in the two regions have been unable to open up the situation. The support and assistance enjoyed by the members is limited, and the degree of satisfaction with the cooperatives is not high, which in turn results in poor overall trust.

\section{ACKNOWLEDGMENT}

The paper has been completed, thanks in particular to the National Nature Science Foundation of China, Yunnan Planning Office of Philosophy and Social Science and Yunnan Normal University. And the same time thanks to the teachers and students of the group.

\section{REFERENCES}

[1] Yexi Chen, Hang Ye,Dingding Wang. The measure of trust level and its influence on cooperation - Evidence from a set of experimental micro data[J]. Management World, 2010(4), pp 54-64.

[2] Yue Chen, Kan Shi, Dongxia Luo The maintenance and repair of trust in organizations [J]. Advances in Psychological Science, 2010, 18(4): pp 664-670.

[3] Xiaobo Dong,Empirical Research on the Relationship between Collective Innovation and Operational Performance of Senior Management Team of Peasants' Specialized Cooperatives. Agricultural Technology \& Economy, 2010(8): pp 117-122.

[4] Yanping Du, Kuiwu Wang, et al. Study on trust in the development of farmer cooperatives[J]. Management of Agricultural Science and Technology, 2012, 31(6): pp 62-64.

[5] Limin Duan, Xuexi Huo. A review of domestic research literature of farmers' cooperatives in China[J].Technology Economics and Management Research,2012(3): pp 91-95.

[6] Linzhen Gan, Rongbiao Cheng. Gray correlation analysis of trust degree and cooperation satisfaction among members of farmers' professional cooperatives. Modern Agricultural Science and Technology, 2016(14): pp 290-292. 